\title{
THE EFFECT OF SELECTED LIFESTYLE FACTORS AND DIET ON MORTALITY OF MEN WITH DOCUMENTED PHYSICAL FITNESS IN THE CITY OFŁÓDŹ
}

JANUSZ ŚMIGIELSKI ${ }^{1}$, ANNA JEGIER ${ }^{2}$, WOJCIECH HANKE ${ }^{3}$, WOJCIECH BIELECKI ${ }^{4}$, and WOJCIECH DRYGAS ${ }^{5}$

${ }^{1}$ Medical University of Lodz, Łódź, Poland

Department of Computer Science and Medical Statistics

${ }^{2}$ Medical University of Lodz, Łódź, Poland

Department of Sports Medicine

${ }^{3}$ Medical University of Lodz, Łódź, Poland

Department of Computer Science and Medical Statistics

${ }^{4}$ Medical University of Lodz, Łódź, Poland

Department of Social Pathologies

${ }^{5}$ Medical University of Lodz, Łódź, Poland

Department of Preventive Medicine

\begin{abstract}
Introduction: It is still uncertain if having at least moderate physical fitness is a necessary and sufficient condition for lowering the risk of death. The aforementioned statement constituted the basis for undertaking the study concerning the effect of particular health-related behaviours on the likelihood of survival in subjects with a moderate and high physical fitness. Materials and Methods: The study sample, i.e. 204 men aged 30-59 years living in Łódź, Poland, was selected within the CINDI WHO Programme and examined over the years 1980-1990 and 2003-2004. In each subject approximate values of one week energy expenditures associated with performing physical exercise of at least moderate intensity ( $>1000 \mathrm{kcal} /$ week) were estimated. Physical efficiency in the study group was evaluated basing on the results of the submaximal effort test. Information about selected socio-demographic characteristics, consumption of alcohol, cigarette smoking and diet was gathered. The vital status of the examined sample was checked in 2009. The Cox proportional hazards regression model was used to identify factors which influence the survival of examined population. Results: The probability of death was more than fourfold higher in the case of individuals who eat "beef or pork meat", as compared to those who consumed these products rarely or never. On the other hand, the subjects who declared regular consumption of yellow cheese had nearly fourfold lower death probability. Current smoking was found to be a significant negative risk factor while moderate consumption of beer a protective one. The level of physical fitness $\left(\mathrm{V}_{\mathrm{O} 2 \max }\right)$ did not significantly influence mortality. Conclusions: The results of the performed analyses indicate negative effect associated with consumption of beef/pork meat and smoking. Furthermore, the data pertaining to the consumption of yellow cheese as a potent protective factor for men's health requires further verification. The possibility that it is some lifestyle proxy rather than a causal factor cannot be excluded.
\end{abstract}

Key words:

Physical activity, Nutritional habits, Alcohol consumption, Tobacco smoking, Pro-health behaviours, Physical fitness

Received: February 18, 2013. Accepted: May 23, 2013.

Corresponding author: J. Śmigielski, Department of Computer Science and Medical Statistics, Medical University of Lodz, Plac Hallera 1, 90-647 Łódź, Poland (e-mail: janusz.smigielski@umed.lodz.pl). 


\section{INTRODUCTION}

The positive role of regular physical activity on health has been approved by authoritative organisations and scientific societies such as the World Health Organisation (WHO) or the American Heart Association (AHA) and has been warmly welcomed by a number of scientific institutions, clinics and cardiac rehabilitation centres [1-5]. The Canadian Medical Association Journal (CMAJ) has published a thorough review of studies on the correlation between physical activity and parameters pertaining to health status. They have revealed that regular physical exercises reduce the overall mortality rate even by $50 \%$. What is interesting, the likelihood of premature death in a subject with cardiovascular risk factors who regularly takes exercise is lower as compared to that of a person with similar problems leading a sedentary lifestyle [6]. It is also worth mentioning that the so called objective indicators of physical fitness (among others, the level of physical fitness) correlate with the risk of death. Physical fitness understood as the capability to perform everyday activities, is usually evaluated with subjective and objective methods including: strength of hand clenching, pace of walking, the time of standing up from a chair and the time of maintaining standing balance (standing balance test). A growing number of evidence shows that the latter are the indicators of general health status [7].

On the other hand, it is still uncertain if having at least moderate physical fitness is a necessary and sufficient condition for lowering the risk of death. Can it be a stand-alone factor or should it be accompanied by other protective lifestyle and diet factors? In other words, the classical mortality risk factors work in a similar way in physically active men as in general population?

The aforementioned questions constituted the basis for undertaking the study concerning the effect of particular health-related behaviours on the likelihood of survival in subjects with a different level of physical fitness.
This issue seems to be important because the authors have not found similar analyses in Polish literature.

\section{MATERIALS AND METHODS}

The study group was selected basing on the data derived from the studies within the Countrywide Integrated Noncommunicable Diseases Intervention (CINDI) programme for the World Health Organisation (WHO). On the basis of the declared self-assessment of health status and documented physical effort, 305 men aged 3059 years attending the Outpatient Department of the Healthy Man in Łódź in the years 1980-1990 were identified. For each subject approximate values of energy expenditures within one week associated with performance of physical exercise of at least moderate intensity (> $1000 \mathrm{kcal} /$ week) were estimated basing on expert evaluation. Physical fitness in the study group was evaluated by the use of the submaximal effort test performed on the bicycle ergometer at $85 \%$ of the Physical Working Capacity (PWC), max HR and the indirect assessment of the maximal oxygen uptake $\left(\mathrm{V}_{\mathrm{O}_{2} \max }\right)$ according to the Astrand method and was interpreted basing on the criteria proposed by Kozłowski [8]. The results of physical fitness were available for 204 men, re-examined in 2003-2005. Respondents' participation in two previous evaluations of physical activity (the first study was performed in 1980-1990, the second one in 2003-2005) was a mandatory requirement in order to become qualified for the study group [9].

Information about selected socio-demographic characteristics (age, place of living), consumption of alcohol (spirits, wine, beer), cigarette smoking (at present and in the past) and a type of diet (the type of fat used for cooking and daily consumption of yellow cheese) was gathered. The diet related questions included inquiry about the type and patterns (amount and frequency) of meat (pork, beef or chicken), white or yellow cheese, 
fish, cakes, margarine, as well as additional use of salt. Alcohol use patterns were provided by the respondents' answers to the questions about consumption of spirits (never vs. moderate use); beer (never vs. moderate use); and wine (never vs. moderate use). Smoking status was also reported (non-smoker, ex-smoker, current smoker). Anthropometric measurements considered height and body mass on the basis of which Body Mass Index (BMI) was calculated.

\section{Analysis of mortality data}

Data on specific causes of men's deaths was received from the Central Statistical Office of Poland (GUS).

\section{Statistical analysis}

The following nonparametric tests of significance were used in the study: generalization Gehan Wilcoxon test, Cox-Mantel test, log-rank test (log rank); generalization Peto and Peto Wilcoxon test and Cox's F test.

In order to investigate the combined effect of the analysed variables and to determine the size of the impact of these variables (as a hazard ratio), it was decided to design a statistical model containing several variables of eating habits. For the multivariate analysis Cox proportional hazards model was used [10].

In Cox proportional hazards model it is assumed that in addition to the hazard function $\lambda_{0}(\mathrm{x})$, the observation is still a subject to a set of $i$-dimensional vector:

$$
\mathrm{y}=\left(\mathrm{y}_{1}, \mathrm{y}_{2}, \ldots, \mathrm{y}_{\mathrm{t}}\right)^{\mathrm{T}}
$$

where:

$\mathrm{T}$ - random variable,

$\mathrm{y}$ - explanatory variable.

In practice, such a vector can be defined, for example, as a patient characteristics, which mostly concern demographic variables, medical or environmental determinants. Furthermore, let $\lambda(y)$ denote the hazard function of the random variable T. In the Cox model:

$$
\lambda(\mathrm{x} ; \mathrm{y})=\lambda_{0}(\mathrm{x}) \exp \left(\beta^{\mathrm{T}} \times \mathrm{y}\right)
$$

where:

$\beta^{\mathrm{T}}$ - vector of regression parameters,

$\lambda_{0}(\mathrm{x})$ - identical hazard function when $\mathrm{y}=0$ for all random variables T.

Because $\lambda_{0}(\mathrm{x})$ remains unspecified, models described by this equation are called semi-parametric models.

As a strategy of composition, the multiple regression models backward stepwise procedure was used. At the starting point, the full model containing variables from the univariate analyses and suggested by the subject literature was built. On each step one variable with the greatest $p$-value was eliminated from the model. The procedure stopped when none of the variables fulfilled cut-off criteria $p>0.2$. The difference between the two survival functions was considered statistically significant if $p>0.05$. In this work, the statistical calculations were performed using STATISTICA 8.0. All variables statistically significant in the univariate analyses were entered to the multivariate model.

\section{RESULTS}

\section{Characterisation of the examined population}

The median age of the subjects at the time of first examination was 54 years and the mean age was 55 years (standard deviation (SD): 11 years). All the examined subjects were living in Łódź urban area. The average physical fitness was 3.20 $1 / \mathrm{min} ; \mathrm{SD}=0.65 \mathrm{l} / \mathrm{min}$. Physical fitness for all subjects was above the lower limit for high level group determined for each age group. The criteria for very high level of physical fitness were met by $90 \%, 32,9 \%$ and $20,5 \%$ of men in age groups 40-49, 50-59 and above 60 respectively (Table 1).

Cardiovascular diseases and cancers were the main causes of death in the group under study, similarly to the entire male population in Poland. Out of 16 deaths, 7 men died of cardiovascular diseases and 5 of cancers ( 0.43 and 0.31 ). Due to a too low number of deaths and a relatively short period of study (2004-2009 years), the overall mortality rate was analysed. 
Table 1. Physical fitness $\left(\mathrm{V}_{\mathrm{O}_{2} \max }\right)$ tests results by age groups

\begin{tabular}{lcccccccc}
\hline \multirow{2}{*}{$\begin{array}{c}\text { Age group } \\
\text { (years) }\end{array}$} & $\begin{array}{c}\text { Respondents } \\
(\mathrm{n})\end{array}$ & $\begin{array}{c}\mathrm{V}_{\text {O2max }} \\
\mathrm{M} \pm \mathrm{SD} \\
(\mathrm{l} / \mathrm{min})\end{array}$ & $\begin{array}{c}\text { lower limit } \\
(\mathrm{l} / \mathrm{min})\end{array}$ & $\mathrm{n}$ & $\%$ & $\begin{array}{c}\text { Hery high physical fitness } \\
\text { lower limit } \\
(1 / \mathrm{min})\end{array}$ & $\mathrm{n}$ & $\%$ \\
\hline $40-49$ & 50 & $5.075 \pm 0.54$ & 3.10 & 5 & 10.0 & 3.390 & 45 & 90.0 \\
$50-59$ & 76 & $3.106 \pm 0.40$ & 2.80 & 51 & 67.1 & 3.090 & 25 & 32.9 \\
$\geq 60$ & 78 & $2.730 \pm 0.20$ & 2.50 & 62 & 79.5 & 2.809 & 16 & 20.5 \\
\hline
\end{tabular}

$\mathrm{M}$ - mean; SD - standard deviation.

Diet

The results for diet related factors showed that the variable "type of fat used for cooking at home" was a significant determinant of life duration. A favourable effect of using vegetable oil and olive oil as compared to other fats was observed (Table 2, Figure 1).

Table 2. The Cox proportional hazards regression model for mortality of men in the city of Łódź - the results of univariate analyses

\begin{tabular}{|c|c|c|c|c|c|}
\hline \multirow[b]{2}{*}{ Explanatory variables: } & \multicolumn{5}{|c|}{$\begin{array}{l}\text { Dependent variable: observation time (months) } \\
\text { (numerical characteristics of the model) }\end{array}$} \\
\hline & $\begin{array}{c}\beta \text { parameter } \\
\text { estimates } \\
\text { (value) }\end{array}$ & $\begin{array}{l}\text { asymptotic } \\
\text { standard } \\
\text { error of } \\
\text { parameters }\end{array}$ & hazard ratio & $\begin{array}{l}\text { Wald statistic } \\
\text { value }\end{array}$ & $\begin{array}{l}\text { probability } \\
\text { level of the } \\
\text { Wald statistic }\end{array}$ \\
\hline Age (continuous variable) & 0.170 & 0.035 & 1.18 & 22.80 & 0.0001 \\
\hline Education (primary education vs. more than primary) & -0.025 & 0.416 & 0.97 & 0.06 & 0.9550 \\
\hline BMI ( $\leq 30$ vs. $>30)$ & 0.040 & 0.760 & 1.04 & 0.01 & 0.9560 \\
\hline Type of fat used at home (margarine vs. oil, olive, vegetable oil) & 0.920 & 0.420 & 2.26 & 4.80 & 0.0360 \\
\hline Spirits (never vs. moderate use) & 0.277 & 0.755 & 1.32 & 0.14 & 0.7130 \\
\hline Beer drinking (never vs. moderate use ) & -1.492 & 0.500 & 0.22 & 8.76 & 0.0030 \\
\hline Wine drinking (never vs. moderate use) & -0.520 & 0.539 & 0.60 & 0.93 & 0.3340 \\
\hline $\begin{array}{l}\text { Pork or beef (not more than } 2 \text { times vs. } 3-5 \text { times } \\
\text { vs. 6-7 times/week) }\end{array}$ & 1.840 & 0.900 & 6.32 & 4.18 & 0.0490 \\
\hline Yellow cheese (never vs. 1-2 vs. 3-7 days/week & -1.111 & 0.516 & 0.33 & 4.63 & 0.0310 \\
\hline Tobacco smoking (nonsmokers vs. exsmokers vs. smokers) & 1.230 & 0.264 & 3.42 & 21.65 & 0.0001 \\
\hline Vegetables & -0.376 & 0.313 & 0.68 & 1.44 & 0.2300 \\
\hline White cheese (never vs. 1-2 vs. 3-7 days/week & 0.339 & 0.321 & 1.40 & 1.12 & 0.2900 \\
\hline Cakes, sweets (never vs. 1-2 vs. 3-7 days/week) & 0.078 & 0.352 & 0.84 & 0.05 & 0.8240 \\
\hline Fruit juices (never vs. 1-2 vs. 3-7 days/week) & -0.126 & 0.305 & 0.88 & 0.17 & 0.6790 \\
\hline Poultry (never vs. 1-2 vs. 3-7 days/week) & 0.291 & 0.338 & 1.34 & 0.74 & 0.3900 \\
\hline Adding salt to meals (no vs. yes) & -0.310 & 0.577 & 0.73 & 0.29 & 0.5920 \\
\hline $\mathrm{V}_{\mathrm{O}_{2} \max }$ & -5.464 & 1.822 & 0.01 & 8.99 & 0.0040 \\
\hline
\end{tabular}




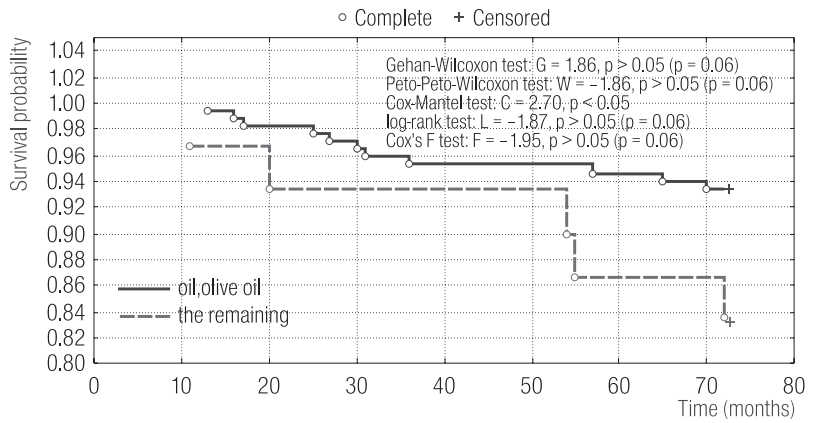

Fig. 1. Survival probability in the group of men, residents of Łódź, with documented physical fitness according to the variable "type of fat used for cooking at home"

Among subjects declaring consumption of yellow cheese, no differences in life duration were observed in relation to the frequency of consumption of this product. However, the fact of eating yellow cheese in comparison with lack of its consumption was a statistically significant factor, which positively influenced chances for survival (in 3 out of 4 cases) (Table 2, Figure 2). Bearing in mind the aforementioned result, it can be stated that the individuals reporting consumption of yellow cheese achieved higher values of predicted life expectancy. On the other hand, frequent consumption of beef or pork negatively influenced survival (Table 2). Amount and frequency of consumption of chicken, fish as well as cakes, vegetables and fruits type or additional use of salt did not influence life expectancy.

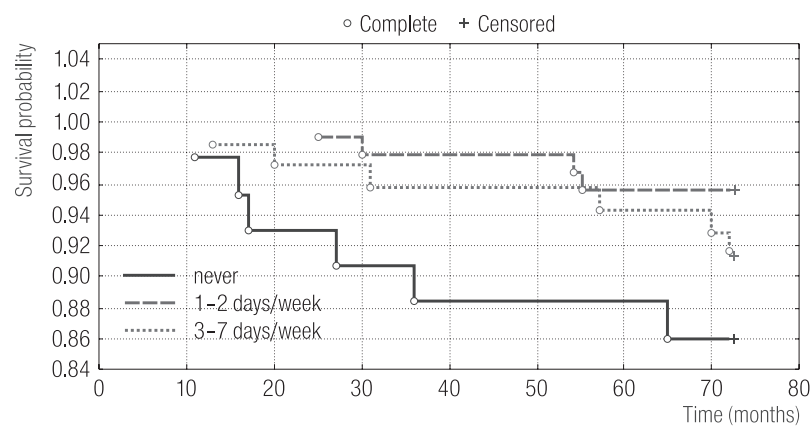

Fig. 2. Survival probability according to the variable "yellow cheese"

\section{Alcohol}

The results of the statistical analysis concerning this group of risk factors showed that only drinking beer exerts a statistically significant positive impact (Table 1, Figure 3) on the subjects' lifespan. Consumption of wine or spirits does not provide the basis for displaying statistically significant differences in life duration

\section{Tobacco smoking}

Both current and formers smoking negatively influenced probability of survival (Table 2, Figure 4).

\section{Body Mass Index}

The results for the variable "BMI" demonstrated that it was not a statistically significant determinant of life duration (Table 2, Figure 5).

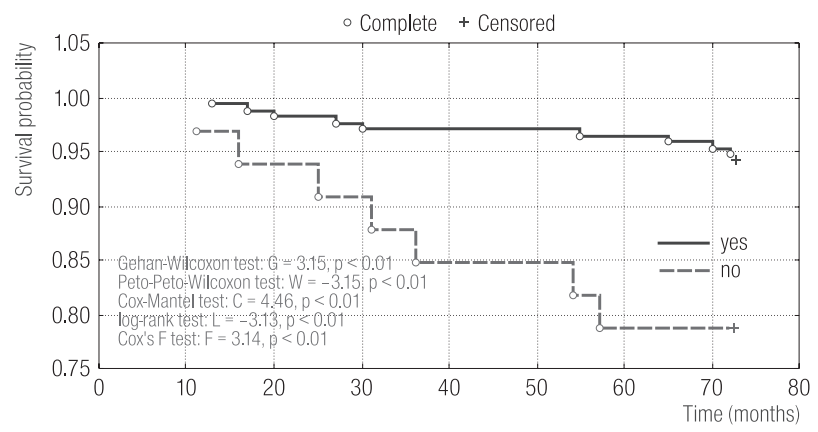

Fig. 3. Survival probability according to the variable "drinking beer"

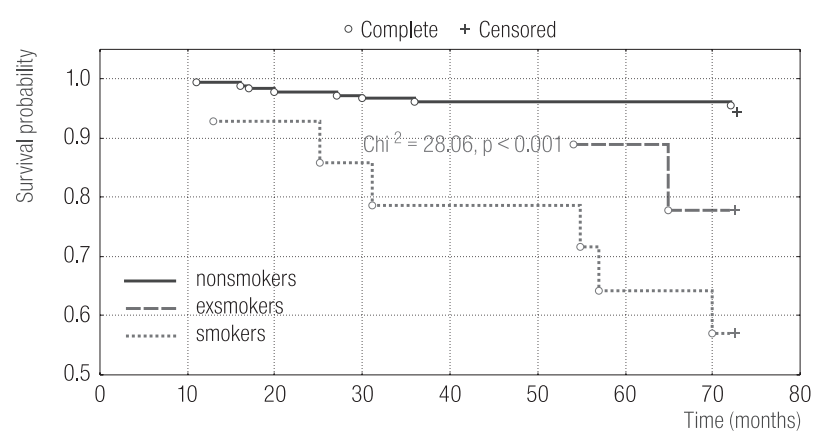

Fig. 4. Survival probability and smoking 


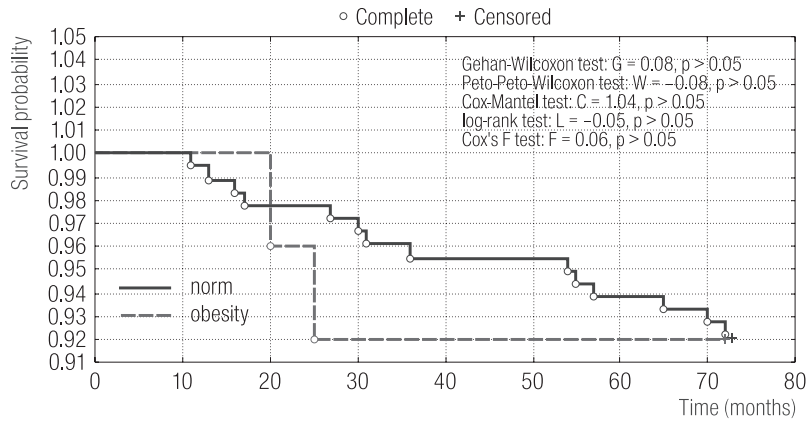

Fig. 5. Survival probability according to the variable "BMI > 30"

\section{Multivariate analysis}

The multidimensional statistical analysis of all significant in the univariate analyses variables and the distribution of death rate among male residents of Łódź with documented physical fitness, based on the Cox proportional hazards regression model, allowed to distinguish two diet binary variables: "yellow cheese" and "beef or pork meat", which had the strongest effect on death probability of the examined men. This probability was more than fourfold higher in the case of the individuals who eat "beef or pork meat", as compared to those who consumed these products rarely or never. The opposite correlation was observed for the variable "yellow cheese", which means that the subjects declaring regular consumption of yellow cheese had nearly fourfold lower death probability than those consuming it rarely or never (Table 3). Current smoking was found to be a significant risk factor and moderate beer consumption a protective one. In the multivariate analysis the type of fat used for cooking as well as the level of physical fitness $\left(\mathrm{V}_{\mathrm{O}_{2} \max }\right)$ did not influence mortality in a significant way.

\section{DISCUSSION}

The aim of the present article was to find out the answer to the question whether there were any significant differences in mortality rate among the group of subjects with regular physical activity and which of the analysed factors could be regarded as significant predictors of this phenomenon.

Epidemiological studies conducted in the USA [11-15] explicitly indicate a positive effect of physical activity on general health status and average lifespan.

Table 3. The Cox proportional hazards regression model for mortality of men in the city of Łódź - the results of mutivariate analysis

\begin{tabular}{|c|c|c|c|c|c|}
\hline \multirow[b]{2}{*}{ Explanatory variables } & \multicolumn{5}{|c|}{$\begin{array}{l}\text { Dependent variable: observation time (months) } \\
\text { (numerical characteristics of the model) }\end{array}$} \\
\hline & $\begin{array}{c}\beta \text { parameter } \\
\text { estimates } \\
\text { (value) }\end{array}$ & $\begin{array}{l}\text { asymptotic } \\
\text { standard } \\
\text { error of Beta } \\
\text { parameters }\end{array}$ & hazard ratio & $\begin{array}{l}\text { Wald statistic } \\
\text { value }\end{array}$ & $\begin{array}{l}\text { probability } \\
\text { level of the } \\
\text { Wald statistic }\end{array}$ \\
\hline Age (continues variable) & 0.15 & 0.04 & 1.16 & 18.40 & 0.001 \\
\hline Yellow cheese (never vs. $1-2$ vs. 3-7 days/week) & -1.55 & 0.71 & 0.21 & 4.77 & 0.030 \\
\hline $\begin{array}{l}\text { Pork or beef (never more than } 2 \text { times vs. } 3-5 \text { times } \\
\text { vs. } 6-7 \text { times/week) }\end{array}$ & 1.37 & 0.67 & 3.15 & 4.18 & 0.049 \\
\hline $\begin{array}{l}\text { Type of fat used at home (margarine vs. oil, olive, } \\
\text { vegetable oil) }\end{array}$ & 0.71 & 0.51 & 2.03 & 1.94 & 0.165 \\
\hline $\begin{array}{l}\text { Tobacco smoking (nonsmokers vs. exsmokers } \\
\text { vs. smokers) }\end{array}$ & 1.26 & 0.32 & 3.54 & 15.91 & 0.001 \\
\hline Beer drinking (never vs. moderate use) & -1.55 & 0.71 & 0.21 & 4.77 & 0.030 \\
\hline $\mathrm{V}_{\mathrm{O}_{2} \max }$ & -0.46 & 1.38 & 0.63 & 0.11 & 0.738 \\
\hline
\end{tabular}

Evaluation of fitting the model to empirical data: $\mathrm{Chi}^{2}$ test $=50.37 ; \mathrm{p}=0.0001$. 


\section{Diet and mortality}

Undoubtedly, rich in simple sugars and saturated fatty acids diet contributes to an increased mortality not only due to the cardiovascular diseases but also to some cancers. Are the same regularities observed in the subjects with documented physical activity? The results of the present study do not fully confirm this concept. Admittedly, a protective effect of oil and olive oil in comparison to other fats, and negative effect of beef meat have been evidenced. On the other hand, it was shown that individuals who regularly consume yellow cheese had three times higher survival probability than the subjects who do not consume this product.

In general, consumption of whole fat dairy products, including yellow cheese, has been not recommended by medical professionals as there is positive correlation between these products and coronary heart diseases. On the other hand, recently it has been reported that excessive cheese consumption, despite high lipid content, reduces LDL cholesterol when compared with butter intake of equal fat content [16]. It is also possible that "yellow cheese consumption" is a proxy measure of some unmeasured lifestyle characteristic.

\section{Alcohol beverages consumption and mortality}

Higher consumption of wine, especially red one, should be interpreted as positive since protective properties of wine which decreases the risk of cardiovascular diseases, improves the functions of the digestive system as well as physical and mental well being have been known for ages. The mechanisms of action of substances contained in grapes, antioxidant properties of polyphenols and their significance as scavengers of excessive reactive oxygen species (ROS) from the organism have been the subject of numerous studies for the last decades [9]. Polyphenols are carriers of organoleptic properties of wine. Tannins make the wine taste bitter due to the precipitation process of salivary proteins and their binding to water. Wine should be also drunk because of health benefits of polyphenols. As a number of studies show, polyphenol-rich diet is characterised by platelet anti-aggregational activity as well as anti-inflammatory (protection against oxidation of LDL cholesterol molecules and polyunsaturated fatty acids) and anti-carcinogenic properties. Resveratrol, a strong antioxidant, is frequently mentioned among wine bioactive substances [17]. The American Dietary Association has reported that daily consumption of wine should be $240 \mathrm{~g}$, which will result in a reduced blood platelet aggregation [18].

The results of our study did not provide an argument supporting protective effects of moderate consumption of wine. It is probably due to misclassification of wine consumption based on reported patterns - some of the moderate drinkers might in fact be rather heavy drinkers.

There are not many reports in the literature dealing with the relationship between beer consumption and the general health status, although the norms for the recommended alcohol intake can be frequently encountered in different studies. Thus, according to the most frequently reported patterns of pure alcohol consumption ( $40 \mathrm{~g}$ for men), a moderate intake of beer should not exceed two glasses daily [19].

The present study revealed that consumption of beer significantly decreases mortality among individuals with documented physical activity. A similar effect has not been demonstrated for other types of alcohol. The observed 'protective' effect of drinking beer may be due to some other lifestyle characteristics strongly connected with beer consumption.

\section{Tobacco smoking and mortality}

Negative effect of tobacco smoking on mortality, lifespan and a general health status is indisputable. The results indicate that smoking addiction significantly increases mortality rate also in subjects with documented physical activity. They are in compliance with the literature reports and reveal a negative effect of tobacco smoking on the general health status and average lifespan [20,21]. 


\section{Physical activity, proper body mass and mortality}

It is generally believed that regular physical effort of adequate intensity, frequency and duration is a significant factor preventing development of obesity [22]. Results of long- lasting prospective studies present that obesity and metabolic syndrome in middle-aged men depend on both the training volume and the level of physical fitness. Training associated with energy expenditure above $2000 \mathrm{kcal} /$ week, accompanied by a high level of oxygen efficiency constitutes a protective factor in development of obesity and metabolic syndrome. In men with the highest level of physical activity, there is a two-three-fold lower risk of obesity and metabolic syndrome occurrence in the middle age, while numerous anthropometric and efficiency indices make this age group resemble persons 10 20 years younger [9]. A negative correlation between physical activity and obesity has been confirmed in numerous scientific publications. What is more, according to the social opinion, regular sports activities are a natural "medication" in controlling overweight and obesity [23,24].

The present study displayed that, in the group of men with documented physical activity, BMI indicating obesity was negatively related (although not significantly) to the lower probability of survival. Analogous results were also achieved for individuals with documented low physical activity [24,25].

\section{Strengths and shortcomings of the study.}

The presented study has its strengths. It is one of the few in the literature which evaluate the survival of group of men with well documented physical activity (at the level above $1000 \mathrm{kcal} /$ week in relation to several health risk factors and high physical fitness test results). The wide range of diet related characteristics, as well as alcohol consumption and tobacco smoking were evaluated as potential risk factors. All the examined elements were evaluated prospectively on two occasions (1980-1990 and 2003-2005). On the other hand, the study has also several limitations. The size of the group was rather small (however sufficient in order to document the effects of several diet related and behavioural factors). Survival analyses were based on short follow-up period (2004-2009) and therefore, probably due to the small number of deaths, evaluation of the role of diet risk factors was rather limited. For the same reasons data on general mortality was taken into account, even though data concerning deaths from cardiovascular diseases would be more appropriate.

\section{Summing up}

The study results suggest that protective effect of physical activity may be significantly limited by smoking addiction. However, the size of the study group and a rather short follow-up period do not provide possibility to analyse interaction between physical fitness and lifestyle characteristics. According to our results, consumption of moderate amounts of wine has not exerted a significant protective effect on mortality rate of men with documented physical activity. However, the pattern of wine consumption could be misclassified when reported by the subjects to health professionals. The results of the performed analyses indicate the protective effect of rich in natural oil and olive oil diet in men and negative effect associated with consumption of beef meat. Furthermore, the data pertaining to the consumption of yellow cheese as a potent protective factor for men's health requires further verification. The possibility that it is some lifestyle proxy cannot be excluded.

\section{REFERENCES}

1. Shiroma EJi I-Min Lee. Physical activity and cardiovascular health. Lessons learned from epidemiological studies across age, gender, and race/ethnicity. Circulation. 2010;122:743-52, http://dx.doi.org/10.1161/CIRCULATIONAHA.109.914721.

2. Mathieu RA 4th, Powell-Wiley TM, Ayers CR, McGuire DK, Khera A, Das SR, et al. Physical activity participation, health perceptions, and cardiovascular disease mortality in a multiethnic population: The Dallas Heart Study. Am Heart J. 2012;163:103740, http://dx.doi.org/10.1016/j.ahj.2012.03.005. 
3. Cooper R, Kuh D, Hardy R. Objectively measured physical capability levels and mortality: Systematic review and metaanalysis. BMJ. 2010;341:c4467, http://dx.doi.org/10.1136/ bmj.c4467.

4. Lee I-M, Shiroma EJ, Lobelo F, Puska P, Blair SN, Katzmarzyk PT. Effect of physical inactivity on major non-communicable diseases worldwide: an analysis of burden of disease and life expectancy. Lancet. 2012;380:219-29, http://dx.doi. org/10.1016/S0140-6736(12)61031-9.

5. World Health Organization. Noncommunicable diseases country profiles 2011. WHO Library Cataloguing-in Publication Data. Geneva: World Health Organization; 2011.

6. Bielecki W, Drygas W. [Regular physical activity and ischemic disease (CHNS) - do we know all about them?] [cited 2012 Jan 15]. Available from: http://pamietajosercu.pl/artykuly/profilaktyka/systematyczna_aktywnosc_ruchowa_a_ choroba_niedokrwienna_serca_chns_-_czy_na_pewno_ wiemy_juz_wszystko_2.html. Polish.

7. Cooper R, Kuh D, Hardy R. Mortality review group. Objectively measured physical capability levels and mortality: Systematic review and meta-analysis. BMJ. 2010;341:c4467, http://dx.doi.org/10.1136/bmj.c4467.

8. Kozłowski S, Nazar K. [Introduction to clinical physiology]. Warszawa: Wydawnictwo Lekarskie PZWL; 1999. Polish.

9. Drygas W, Jegier A, Bednarek-Gejo A, Kwaśniewska M, Dziankowska-Zaborszczyk E, Kostka T. [The level of physical activity as a factor determining obesity and metabolic syndrome occurrence in middle-aged men. The outcome of long-term prospective studies]. Przegl Lek. 2005;62(3):8-13. Polish.

10. Sawyer S. Nonparametric survival analysis: Cox-Mantel tests and Permutation tests, Washington University [cited 2012 Jan 15]. Available from URL: http://www.math. wustl.edu/ sawyer/handouts/survrank.pdf.

11. Morris JN, Everitt MG, Pollard R, Chave SP. Vigorous exercise in leisure time: protection against coronary heart disease. Lancet. 1980;2:1207-10, http://dx.doi.org/10.1016/ S0140-6736(80)92476-9.
12. Paffenbarger RS Jr., Hyde RT, Wing AL, Lee IM, Jung DL, Kampert JB. The association of changes in physical-activity level and other lifestyle characteristics with mortality among men. N Engl J Med. 1993;328:538-45, http://dx.doi. org/10.1056/NEJM199302253280804.

13. Schnohr P, Scharling H., Jensen JS. Changes in leisure-time physical activity and risk of death: An observational study of 7,000 men and women. Am J Epidemiol. 2003;158(7): 639-44, http://dx.doi.org/10.1093/aje/kwg207.

14. Blair SN, Kohl HW 3rd, Paffenbarger RS Jr., Clark DG, Cooper KH, Gibbons LW. Physical fitness and all-cause mortlaity. A prospective study of healthy men and women. JAMA. 1989;262(17):2395-401， http://dx.doi.org/10.1001/ jama.1989.03430170057028.

15. Blair SN, Kohl HW 3rd, Barlow CE, Paffenbarger RS Jr., Gibbons LW, Macera CA. Changes in physical fitness and all-cause mortality. A prospective study of healthy and unhealthy men. JAMA. 1995;273:1093-8, http://dx.doi. org/10.1001/jama.273.14.1093.

16. Petyaev IM, Bashmakov YK. Could cheese be the missing piece in the French paradox puzzle? Med Hypotheses. 2012;79(6):746-9, http://dx.doi.org/10.1016/j.mehy.2012. 08.018 .

17. Kudełka W, Hajduk K. [Structure of wine consumption in Poland]. Zesz Nauk. 2006;705:101-10. Polish.

18. Janicki A. [Functional food - nutritional need or promotion of new products]. Bezpiecz Zywnosc. 2001;1:5-8. Polish.

19. Centers for Disease Control and Prevention. Quitting smoking among adults - United States, 2001-2010. MMWR Morb Mortal Wkly Rep. 2011[cited 2012 Jan 17];60(44). Available from URL: http://www.cdc.gov/mmwr/pdf/wk/mm6044.pdf.

20. Steinberg MB, Delnevo CD. Tobacco smoke by any other name is still as deadly. Ann Intern Med. 2010;152(4):259-60, http://dx.doi.org/10.1059/0003-4819-152-4-201002160-00011.

21. Centers for Disease Control and Prevention. Quitting smoking among adults - United States, 2001-2010. MMWR Morb Mortal Wkly Rep. 2011 [cited 2012 Jan 20]; 60(44). Available from URL: http://www.cdc.gov/mmwr/pdf/wk/mm6044.pdf. 
22. Shiroma EJ, Lee I-Min. Physical activity and cardiovascular health. Lessons learned from epidemiological studies across age, gender, and race/ethnicity. Circulation. 2010;122:743-52, http://dx.doi.org/10.1161/CIRCULATIONAHA.109.914721.

23. Metkus TS Jr., Baughman KL, Thompson PD. Exercise prescription and primary prevention of cardiovascular disease. Circulation. 2010;121:2601-4, http://dx.doi.org/10.1161/CIRCULATIONAHA.109.903377.
24. Wei M, Kampert JB, Barlow CE, Nichaman MZ, Gibbons LW, Paffenbarger RS, et al. Relationship between low cardiorespiratory fitness and mortality in normal-weight, overweight, and obese man. JAMA. 1999 [cited 2012 Jan 20];282(16): 1547-53. Available from URL: http://jama.jamanetwork. com/article. aspx? articleid=192035\#REF-JOC90699-23, http://dx.doi.org/10.1001/jama.282.16.1547.

25. Jordan J, Engeli S. Obesity, hypertension, and cardiovascular health: is there anything poor Cassandra tries to tell us? J Hypertens. 2012;30:1103-5, http://dx.doi.org/10.1097/ HJH.0b013e3283542da0.

This work is available in Open Access model and licensed under a Creative Commons Attribution-NonCommercial 3.0 Poland License - http://creativecommons.org/ licenses/by-nc/3.0/pl/deed.en. 